\title{
High-Throughput Proteomics: A New Tool for Quality and Safety in Fishery Products
}

\author{
Sara Tedesco, William Mullen and Susana Cristobal
}

\section{Linköping University Post Print}

\section{Tweet}

N.B.: When citing this work, cite the original article.

Original Publication:

Sara Tedesco, William Mullen and Susana Cristobal, High-Throughput Proteomics: A New Tool for Quality and Safety in Fishery Products, 2014, Current protein and peptide science, (15), 2, 118-133.

http://dx.doi.org/10.2174/1389203715666140221120219

Copyright: Bentham Science Publishers

http://www.benthamscience.com/

Postprint available at: Linköping University Electronic Press

http://urn.kb.se/resolve?urn=urn:nbn:se:liu:diva-110716 


\title{
High-Throughput Proteomics: A New Tool for Quality and Safety in Fishery Products
}

\author{
Sara Tedesco ${ }^{1, *}$, William Mullen ${ }^{2, \S}$ and Susana Cristobal ${ }^{1,3, \S}$ \\ ${ }^{I}$ Department of Clinical and Experimental Medicine, Health Science Faculty, Linköping University, Linköping, Sweden; \\ ${ }^{2}$ School of life Sciences, College of Medical, Veterinary and Life Sciences, University of Glasgow, Glasgow, UK; \\ ${ }^{3}$ IKERBASQUE, Basque Foundation for Science, Department of Physiology, Faculty of Medicine and Dentistry, \\ University of the Basque Country, Leioa, Spain
}

\begin{abstract}
In order to cope with the increasing demand for fishery products, sensitive technological tools are required to ensure high quality and wholesomeness and to monitor their production process in a sustainable manner while complying with the strict standards imposed by regulatory authorities. Proteomics may assist the industry as it allows an unbiased approach in the discovery of biomarkers that could be used to increase our understanding of different biological, physiological and ecological aspects that may be advantageous in optimizing quality and safety in aquatic species. The aim of this review is to highlight the potential of cost-effective high-throughput technologies, such as those offered by proteomics using "on-line" mass spectrometry to improve the efficiency of the industry in identifying biomarkers relevant for safe high quality products.
\end{abstract}

Keywords: Fishery, biomarker, food quality, mass spectrometry, proteomics, safety, seafood, traceability.

\section{INTRODUCTION}

Consumers are showing an increasing interest in the transparency of food processing, production, safety and marketing [1]. Hence, the Food Agriculture Organization of the United Nations (FAO) and the World Health Organization (WHO) are promoting national food control systems that are based upon scientific principles and guidelines in all sectors of the food chain to achieve improved food safety, quality and nutrition [2].

Seafood is considered a high value foodstuff due to its high content in omega-3 polyunsaturated fatty acids, an excellent source of proteins, vitamins and minerals [3]. In addition, their ability to prevent numerous diseases and to help in foetal an infant development make them increasingly more attractive for human consumption [2].

The increasing demand by the consumers and the depletion of traditional fishery stocks is causing the growth of alternative fishery production methods. Although this increase balances the stagnating supply of seafood from fisheries, it raises several sustainability concerns [4]. An indiscriminate use of production-inputs such as land, water, feeds, energy and xenobiotics can lead to over exploitation of alternative natural resources and hence raising concern on environmental stress [3]. In addition, fisheries, and aquaculture in general, are vulnerable to exogenous shocks to ecosystems such as climate and salinity changes, contamination by

*Address correspondence to this author at the Department of Clinical and Experimental Medicine, Health Science Faculty, Linköping University, Linköping, Sweden; Tel: ??????????; Fax: ???????????;

E-mail: sara.tedesco@liu.se

${ }^{\S}$ These authors contributed equally to this work. pesticides, pharmaceutical or industrial pollutants or oil spills, that can cause severe biologic effects directly on aquatic organisms and can potentially lead to indirect effects further up the food chain for humans consumption [3].

Bostock and colleagues [5] underlined the growing attention to the processes, methods and tools that allow the ecosystem approach to aquaculture principles to be put into practice. Sustainability and environmental balance can be supported by environmental impact assessment (EIA) and risk analysis, through the use of technology and decision support tools, thereby potentially increasing food supply and food security for the population, especially in developing nations. Environmental impact assessment can be defined as: "The process of identifying, predicting, evaluating and mitigating the biophysical, social, and other relevant effects of development proposals prior to major decisions being taken and commitments made" [6]. EIA is therefore important for the identification of mitigation measures that can minimize any possible environmental impact and risk. EIA and monitoring are essential for a better environmental management but unfortunately EIA and monitoring procedures in aquaculture often do not exist, are not sufficiently developed or implemented, and often appear to be inadequately designed to provide key information on changes in the ecological features of the specific environments sustaining given aquaculture practices [7].

Risk analysis in aquaculture is another key tool whose aims include food security, trade, consumer preference for high quality and safe products, production profitability and other investment and development objectives [8].

Proteomic technologies have the advantage of being sensitive and unbiased tools able to discover potential biomarkers for environmental monitoring and risk assessment and 
helping to understand the mechanism of toxicity of environmental pollutants that affect growth, reproduction and health of seafood with repercussion to human health [9].

In particular, environmental proteomics focuses on the analysis of an organism's proteome and the detection of quantitative changes in the individual proteins/peptides [10] in response to environmental shifts, allowing the identification of biomarkers that can be used as tools for environmental assessment and sustainability.

For instance, high-throughput proteomic approaches such as isobaric tagging for relative and absolute quantitation (iTRAQ), has been successfully used to study the responses by fish to aquatic pollutants, including androgen receptor agonists/antagonists [11]. Better understanding of environmental regulators of reproduction, like endocrine disruptors, is therefore important for both aquaculture and conservation of fisheries.

Furthermore, recent successes of proteomic methodologies, especially gel-free proteomics, make them a promising strategy in food sciences, promoting increased interest in the food industry with regard to process optimization, quality safety [12] and nutritional assessment [13].

Proteomics, through the quantitative analysis of protein levels and their dynamic changes in fishery products, can significantly contribute to the understanding of the interdependence between seafood proteome changes during their production or processing and their quality, hence it is possible to determine the critical steps required to optimize the production chain [14].

For example, high-through proteomics has been successfully applied to identify altered protein expression in the muscle of rainbow trout Oncorhynchus mykiss during spawning and was associated with biochemical processes involved in muscle deterioration. This discovery can contribute to the improvement of muscle growth and quality testing in this species [15].

In addition, a high-throughput proteomic application in fishery products has been recently optimized for the fast authentication of all commercial fish species belonging to Merluccidae family. The major fish allergen (Parvalbumin beta, $\beta$-PRVB), can now be detected in less than 2 hours using this technique $[16,17]$. This fast procedure can therefore be used to avoid fraudulent species substitution that can interfere with the quality and value of these products.

In this context, a new discipline, "foodomics" has been defined as "a comprehensive, high-throughput approach for the exploitation of food science with the aim of improving human nutrition", and it has received more and more attention from scientists since 2009, at the time of the first international conference in Cesena, Italy (foodomic.eu) [18].

In a recent review, Cerdà and Manchado summarize how OMICS technologies, included proteomics and foodomics, can better characterize reproduction, development, nutrition, immunity and toxicology of flatfishes to produce in a sustainable and profitable manner, healthy animals as well as high-quality and safe products for the consumer [19].

The number of publications dealing with application of proteomics in aquaculture more than doubled in the period
2007-2011 [19], however most of them are based on electrophoretic techniques such as 1 or 2-DE. Gel-based methods, especially 2-DE, are time-consuming, labour intensive and often evidence difficulties in reproducibility between the gels; nonetheless this approach can facilitate the identification of proteins for non-completely sequenced organisms (i.e. the majority of the species used in aquaculture, Table 1). This approach facilitates protein identification through orthologous proteins from other species or de novo sequencing approach since the comparison of peptides after in-gel digestion is exclusively from the excised band or spot from specific proteins of interest and not from the entire proteome sample. On the other hand, gel-based methods, at the opposite of high-throughput techniques, are not very suitable for aquaculture or fisheries industries where daily screening of numerous seafood samples must be analysed almost automatically in a rapid and sensitive way to guarantee high quality standard products in the market.

The growth of mass spectrometry facilities, powerful bioinformatics tools, and availability of genomic information in research centres and industries can make possible that highthroughput proteomics will feature in aquaculture and fisheries in the near future.

An international research team of numerous scientists has recently published an important achievement in science, the world's first whole genome sequence map of the oyster Crassostrea gigas [20], the first mollusc genome to be sequenced, opening new possibilities for proteomic research and industrial applications in other poorly explored mollusc family species. Although this species is particularly interesting for its high economic value in aquaculture and fishery, also numerous bony fish species are becoming more available in NCBI protein database such as Nile tilapia (Oreochromis niloticus), Atlantic salmon (Salmo salar) and Rainbow trout(Oncorhynchus mykiss), aquaculture species with the highest number of protein sequences [14].

This review intends to discuss and highlight highthroughput proteomics techniques as useful tools for assessment of quality and safety of fishery products.

\section{HIGH-THROUGHPUT MASS SPECTROMETRY APPLICATIONS FOR QUALITY CONTROL IN SEA- FOOD INDUSTRY}

Food quality is a complex concept since it depends on many different parameters.

There are two methods used to classify food quality. One is a subjective measure which includes any characteristics that a consumer would expect the product to have $[1,14]$. The other is a more objective standard that requires the product to meet certain criteria set by the suppliers before it can be deemed to be of quality [21]. Food safety is a very different criteria, as this must ensure that all potential hazards that can impact on consumer health. While all products must meet minimum standards for food safety consumers will be willing to pay extra for food of a higher quality, which requires some form of objective measure, such as confirmation of species by proteomics, as previously discussed.

The study of proteins and peptides provides important information about physiological functions and environmental 
Table 1. Main world aquaculture species.

\begin{tabular}{|c|c|c|c|}
\hline Scientific Name (Common Name) & Proteome $^{b}$ & Genome $^{c}$ & Environment \\
\hline Acipenser baerii (Siberian sturgeon) & $\mathbf{N}$ & $\mathbf{N}$ & Freshwater \\
\hline Anguilla japonica (Japanese eel) & $\mathbf{N}$ & Gene (2), Transcript (2) & Freshwater and Seawater \\
\hline Arapaima gigas (Arapaima) & $\mathbf{N}$ & $\mathbf{N}$ & Freshwater \\
\hline Artemia spp. (Brine shrimps nei) & $\mathbf{N}$ & Gene (2), Transcript (1) & Salted lake \\
\hline Carassius carassius (Crucian carp) & $\mathbf{N}$ & Gene (7), Transcript (7) & Freshwater \\
\hline Catla catla (Catla) & $\mathbf{N}$ & $\mathbf{N}$ & Freshwater \\
\hline Cirrhinus mrigala (Mrigal carp) & $\mathbf{N}$ & $\mathbf{N}$ & Freshwater \\
\hline Clarias gariepinus (North African catfish) & $\mathbf{N}$ & $\mathbf{N}$ & Freshwater \\
\hline Crassostrea gigas (Pacific cupped oyster) & $\mathbf{Y}$ & Gene (5), Transcript (2) & Seawater and Estuary \\
\hline Crassostrea virginica (American cupped oyster) & $\mathbf{N}$ & $\mathbf{N}$ & Seawater and Estuary \\
\hline Ctenopharyngodon idellus (Grass carp) & $\mathbf{N}$ & $\mathbf{N}$ & Freshwater \\
\hline Cyprinus carpio (Common carp) & $\mathbf{N}$ & Gene (9), Transcript (6) & Freshwater \\
\hline Dicentrarchus labrax (European seabass) & $\mathbf{N}$ & Gene (8), Transcript (5) & Seawater, Estuary, Lagoon, Freshwater \\
\hline Hypophthalmichthys molitrix (Silver carp) & $\mathbf{N}$ & $\mathbf{N}$ & Freshwater \\
\hline Hypophthalmichthys nobilis (Bighead carp) & $\mathbf{N}$ & $\mathbf{N}$ & Freshwater \\
\hline Ictalurus punctatus (Channel catfish) & $\mathbf{N}$ & Gene (54), Transcript (5) & Freshwater, Estuary, Seawater \\
\hline Labeo rohita (Roho labeo) & $\mathbf{N}$ & $\mathbf{N}$ & Freshwater \\
\hline Laminaria japonica (Japanese kelp) & $\mathbf{N}$ & $\mathbf{N}$ & Seawater \\
\hline Lates calcarifer (Barramundi) & $\mathbf{N}$ & $\mathbf{N}$ & Freshwater and Estuary \\
\hline Macrobrachium rosenbergi (Giant river prawn) & $\mathbf{N}$ & $\mathbf{N}$ & Freshwater \\
\hline Mercenaria mercenaria (Northern quahog) & $\mathbf{N}$ & $\mathbf{N}$ & Seawater \\
\hline Mugil cephalus (Flathead grey mullet) & $\mathbf{N}$ & Gene (1) & Freshwater, Estuary, Seawater \\
\hline Mytilus edulis (Blue mussel) & $\mathbf{N}$ & $\mathbf{N}$ & Seawater \\
\hline Mytilus galloprovincialis (Mediterranean mussel) & $\mathbf{N}$ & Gene (3), Transcript (3) & Seawater \\
\hline Oncorhynchus kisutch (Coho salmon) & $\mathbf{N}$ & $\mathbf{N}$ & Freshwater, Estuary, Seawater \\
\hline Oncorhynchus mykiss (Rainbow trout) & $\mathbf{N}$ & Gene (102), Transcript (16) & Freshwater, Estuary, Seawater \\
\hline
\end{tabular}


(Table 1) contd....

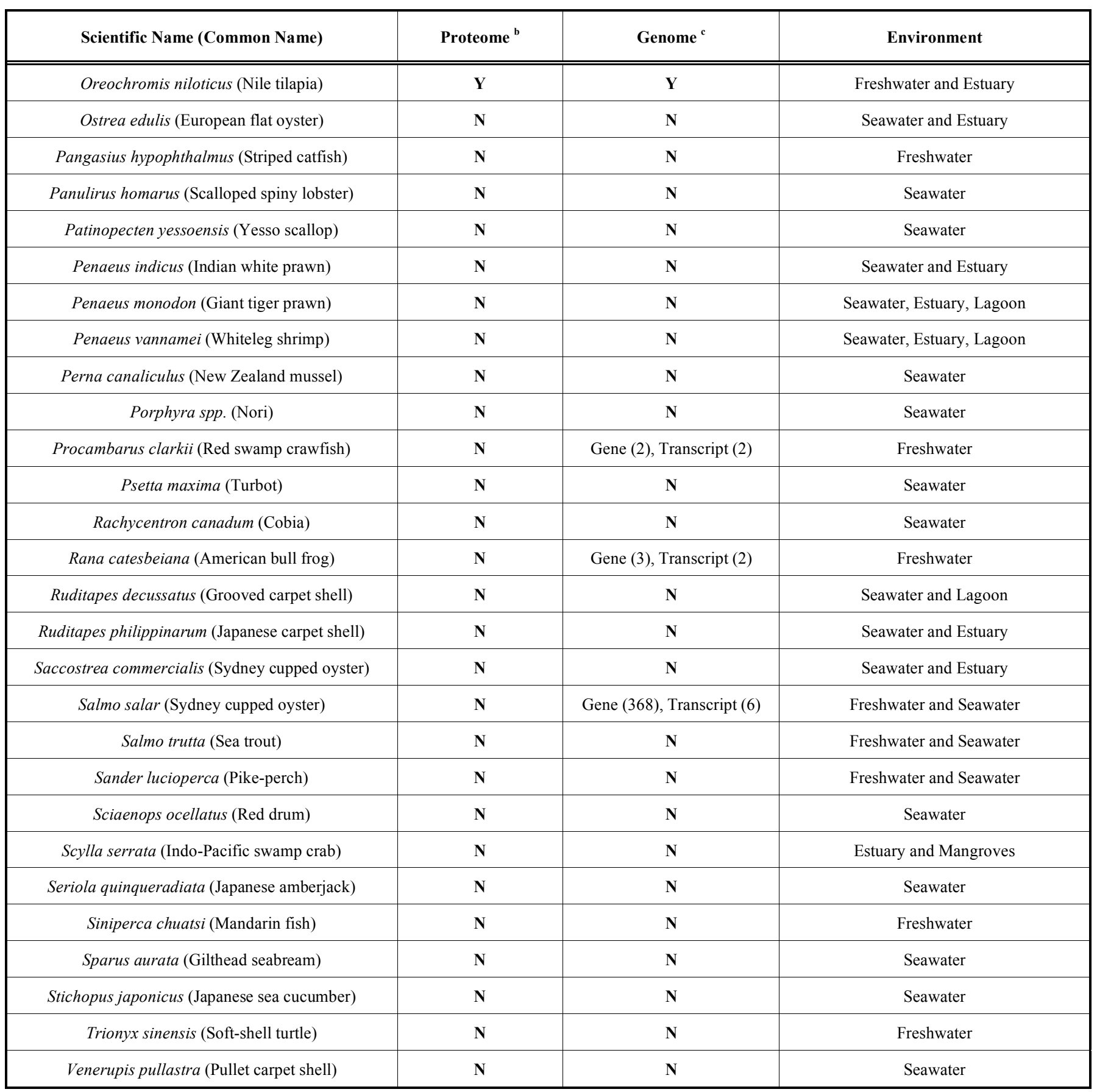

conditions in all living systems that can affect food quality properties [22]. The proteome, in contrast to the genome, is more complex and dynamic, changing in responses to time, cell type and environmental stressors, and is subjected to changes by pre translational and post translational modifications (PTM) [10].

Mass spectrometry (MS)-based proteomics is a powerful tool for the global analysis of protein/peptides composition and PTMs. The study of the dynamic change of proteo$\mathrm{mic} /$ peptidomic expression can therefore contribute to the discovery of potential biomarkers for judging food quality. Food quality has been well described by Pineiro and Martinez [14] and covers a range of seven topics as listed below:
(1) Traceability and authentication (e.g. geographical origin, species);

(2) Nutritional value and wholesomeness (e.g. vitamins, proteins, minerals, fats, digestibility and desirable fatty acid compositions);

(3) Production method (e.g. wild, intensively or organically farmed);

(4) Functionality (e.g., bioactive compounds);

(5) Processing type (e.g., fresh, frozen, canned, smoked, salted);

(6) Organoleptic and sensory attributes (e.g., size, taste, texture, smell, colour); 
(7) Safety (e.g., levels of microbial pathogens, drugs, contaminants, toxins, allergens).

Two different strategies can be carried out: bottom-up and top-down proteomics. In the first strategy, proteins are enzymatically or chemically treated to produce peptides and their MS detection is used to infer protein presence in highthroughput analysis of highly complex samples [23]. At the opposite, top-down proteomics starts with intact mass measurements. Generally the bottom-up strategy is easier when the detection is focused on protein's presence and/or its identification from a database, while the top down strategy is preferable to use when interested to the entire amino acid sequence and relative PTM.

For the assessment of quality control in seafood and fish products, examples of discovered proteins and peptides biomarkers are represented in Fig. (1).

Capillary electrophoresis (CE) has been a proven method of protein separation since it was introduced in the early 1980's [24]. This allowed high-resolution separation of proteins with high selectivity and sensitivity. Although the use of $\mathrm{CE}$ in the analysis of food proteins has progressed, it has not yet been developed to the extent of HPLC. The use of the various methods of CE analysis is discussed in a review by
Recio and colleagues [25]. Traditionally, the detection method used with CE is by monitoring of the UV absorbance output at the end of the capillary. However, this does not provide any information as to the identity of the protein or any potential PTM that may have occurred. The only method of providing this information is MS analysis. Although the coupling of CE to MS was first introduced over 20 years ago [26], it is still not a widespread application in the food and proteomics analysis. A review of "Foodomics" by Herrero [27] listed over $30 \mathrm{MS}$ methodologies for pesticides and antimicrobials in food, none of which used CE. In fact CE-MS proteomic methods account for a single paragraph on the tenth page. So although CE-MS can have numerous applications in food safety and food quality [28] its use in proteomics is limited and therefore its routine use as highthroughput proteomics in food and seafood is just in its infancy. One of the issues arising from this topic is an exact definition of what a high-throughput application actually is. One definition of this term is given on the MASCOT website (http://www.matrixscience.com/pdf/automation.pdf). In short, the data flow is continuous and the results are automatically interpreted without the need for a human operator. While this may be applicable in some instances we are concerned with the complete process of sample handling, sample prepara-

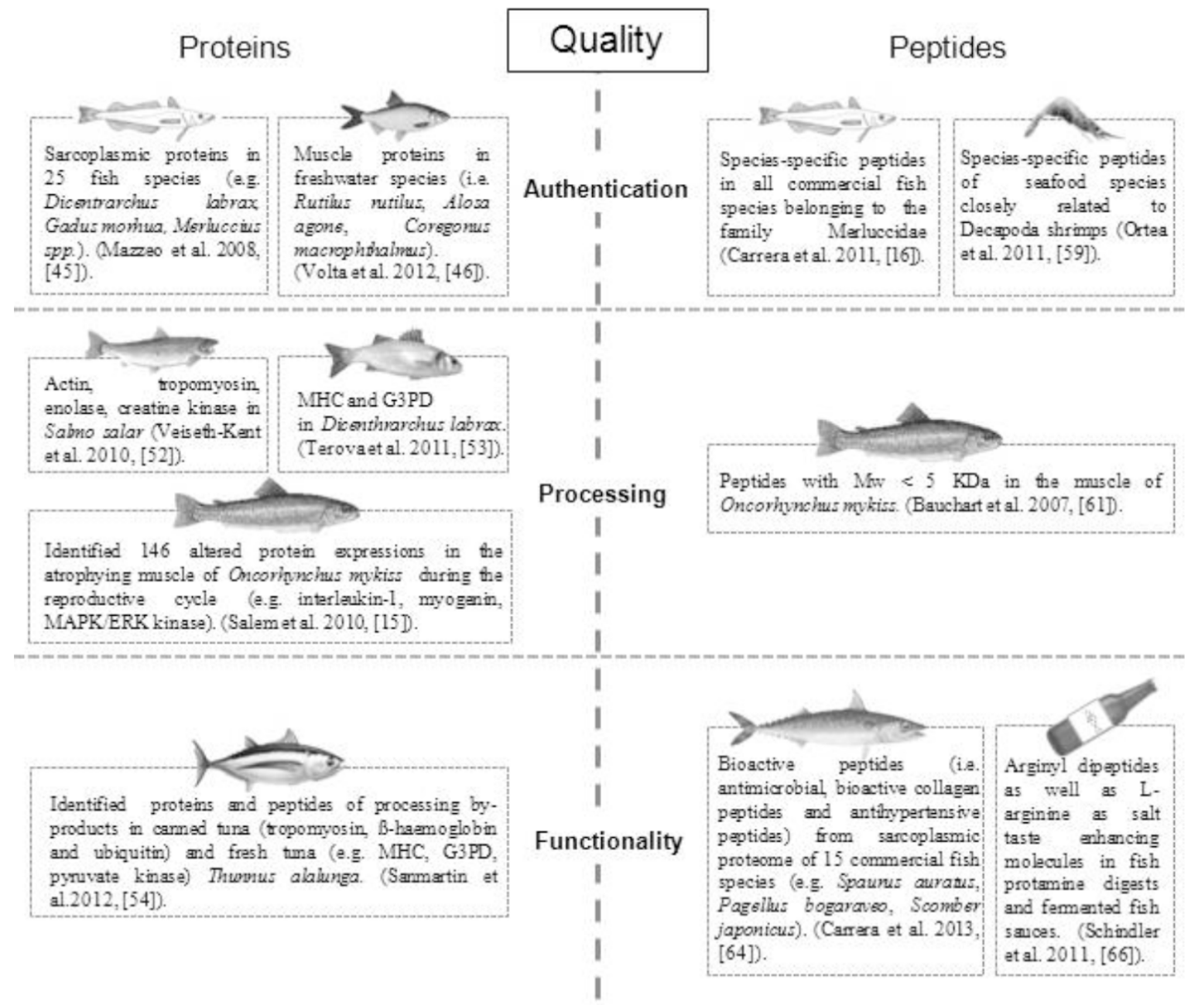

Fig. (1). Examples of discovered protein and peptide biomarkers for quality control of seafood and fish products by MS-based proteomics. 
tion, analysis and data evaluation. All of the components that make up the workflow must be achievable in a timely fashion that allows assessment of the proteomic data from an adequate number of samples to obtain statistically significant results.

The use of CE-MS for high-throughput proteomics has allowed the development of a range of biomarkers of disease to be developed in clinical proteomics [29-31]. However, there are no publications to date using this technique in seafood proteomics or even the wider field of aquaculture. In the cases cited, top-down methodologies are employed to produce fingerprints or panels of biomarkers that can indicate the early onset of a disease. The same process and technology has also recently been applied to the field of veterinary proteomics. Mastitis is one of the major losses of income for the dairy industry and the early detection and treatment with the appropriate antibiotic is required. In a study by Mansor et al. (submitted) they were able to use the low molecular weight milk proteome to identify the presence of mastitis through milk and to differentiate between $E$. coli and $S$. aureus infections. A similar analysis of whole milk was used for the detection and quantification of bovine milk in either ovine or caprine milk by [32]. This publication highlights one of the difficulties of CE-MS for protein analysis, thus the interaction of the negatively charged capillary wall with the positively charged proteins, responsible of band broadening and decreased resolution. A review by Simo et al. in 2005 provides further examples of the use of CE-MS to discriminate between animal species in processed food using a polymer coating of the capillary to enhance resolution [33]. CE-MS in proteomics is an exciting field which, has still to be developed to its full potential. At present the major mass spectrometers being coupled to $\mathrm{CE}$ are Time of Flight (TOF) analysers. While these provide accurate mass measurements there is a need for MS/MS analysis to allow sequencing of peptides and proteins. The sensitivity levels with existing mass spectrometers do not allow extensive MS/MS of peptides and proteins in CE analysis. However, progress is being made with the latest Orbitrap instrumentation and CE-MS sheathless systems that may overcome this limit [34].

Recent developments in column technology have allowed LC to be considered in high-throughput proteomics, as was defined above. Previously, LC analysis would require two orthogonal separation techniques e.g., cation exchange fractionation followed by reverse phase separation, better known as Multidimensional protein identification technology MudPIT [35]. This technique was a major improvement on 2-DE separation as it allows online analysis. However, having multiple LC runs not only takes longer to analyse, it is not ideal for carrying out quantitative comparisons between samples.

The recent introduction of $50 \mathrm{~cm}$ nanoflow columns using longer shallow gradients has dramatically increased the number of proteins that can be identified in a single chromatographic run [36]. In the analysis of the yeast proteome Thakur et al (2011) were able to identify 2990 proteins in a single run shotgun analysis using this separation technique coupled to an Orbitrap mass spectrometer. This degree of separation brings ultra-high pressure $(10,000 \mathrm{psi})$ LC nanoflow systems to work at similar separation capabilities to that of CE. Although CE has a number of advantages over LC for protein analysis [37], the amount of sample that can be loaded into the capillary is limited. This, and electrical connectivity, has prevented the wider use of MS/MS analysis with CE. However it has been shown high efficiency and sensitive peptide analysis when CE and MS were coupled using an electrokinetically pumped ESI sheathflow interface $[38,39]$. We have also recently demonstrated that interfacing a $\mathrm{CE}$ with an Orbitrap Velos MS/MS is possible using the standard Agilent ESI sheathflow interface [40]. There is also one manufacturer's solution to the interfacing problem, Beckman have results from a prototype porous tip sprayer for sheathless CE-MS analysis that were published in 2010 [34]. However, this has still not been launched into the market.

The advent of longer LC columns, combined with ultrahigh pressure pumps and CE interfacing to MS/MS via shealth and sheathless interfaces, will contribute to a further scope to redefine high- throughput proteomics.

\subsection{Proteomics}

Several studies applied the described strategies to improve the research of specific biomarkers for quality in aquaculture food products. The future trend is an optimization of these methodologies for sensitive but especially highthroughput measurements that do not need for example the use of 1 or 2-DE protein separations or other timeconsuming and less reproducible methodologies.

Species authentication, in particular, is one of the major areas of concern in seafood quality that requires tighter guarantees to assure consumer confidence by preventing fraudulent labelling. Regulatory interventions aim at avoiding mislabelling of species or geographic origin or substituting wild fish with farmed fish, to assure transparency of customer requirements.

There are several techniques for authentication in fishery products including DNA-based analysis for species identification, protein/proteomics (1,2 SDS-PAGE, IEF, MS) and nuclear magnetic resonance (NMR) spectroscopy based on lipid composition analysis in order to identify the geographical origin and processing conditions [41]. Studies using gelbased proteomics and immunological methodologies have been extensively applied for the authentication of fish species [42-44] but one of the first gel-free proteomic strategies developed in fish was used by Mazzeo and co-workers [45] who developed a top-down method based on matrix-assisted laser desorption/ionization time of flight (MALDI-TOF) MS. The authors were able to discriminate 25 different commercial fish species by selecting sarcoplasmic proteins with molecular weight about $11 \mathrm{KDa}$ as species-specific biomarkers for their unambiguous identification. A similar but more recent study showed how to discriminate three freshwater fish species (Alosa agone, Coregonus macrophthalmus and Rutilus rutilus) by MALDI-TOF MS using both muscle and liver tissues [46]. Although it was a pilot study, the authors reported on a simple proteomic gel-free strategy performed in a simple single-step extraction procedure, without any further purification.

Furthermore, these species-specific protein mass fingerprints (PMFs) especially in muscle tissues can be extremely 
suitable for routine food controls since freshwater fish species are more commonly commercialized as fillets rather than the whole fish.

Although these high-throughput techniques for fish species identification require minimal time consumption, low cost and can be applied to large-scale screening for control and authentication of fishery products, DNA-based analysis, especially DNA-barcoding, can, most likely, be considered more reliable, cheaper and a more high-throughput technique when compared to the other ones described. The advantage of using DNA-based methods compared to proteins is that DNA is a more stable molecule that can withstand the harsh treatment conditions needed for specific food processes [47]. In fact, this robust technique can be used to genetically identify crustacean, mollusc and fish species in raw, frozen and processed commercial food [48].

The nutritional quality of fish, seafood products and most marine oils, is often associated with their high content of essential fatty acids (e.g., linoleic acid, omega-3 polyunsaturated fatty acids (n-3 PUFAs), eicosapentaenoic acid (EPA), docosahexaenoic acid (DHA)) which contributes to a decreased risk of coronary heart disease and cancer [2].

Proteomic studies have seldom been applied to the nutritional value of food in fishery products. Piñeiro and colleagues suggested that the reason for this may be due to technical difficulties such as high insolubility of seafood proteins, the numerous high molecular proteins, the presence of abundant isoforms and weak ionization levels [49]. However modern proteomic methodologies and strategies can overcome these problems. One of the first studies using MS for the seafood proteome analysis was performed in crayfish calciprotein and some sarcoplasmic proteins from fresh carp fish by fast atom bombardment mass spectrometry (FABMS) and high performance liquid chromatography coupled to electrospray ionization mass spectrometry (HPLC-ESI MS) respectively [50]. However, no nutritional properties were attributed to these proteins [49].

Flesh texture in fish is mainly determined by biological function such as muscle organization, protein content and composition and its quality can be affected by preslaughtering stress, post-mortem deterioration, processing, storage temperature and physiological conditions such as sexual maturation and spawning [51].

Pre-slaughter crowding for 40 min caused an increase in the proteolysis of muscle structural proteins (i.e. actin, light and heavy chain of myosin, tropomyosin) in Atlantic salmon and an increase of enzymes involved in energy production (i.e., enolase, creatine kinase) suggesting an accelerated postmortem $\mathrm{pH}$ decline and rigor mortis contraction of the crowded salmon [52]. The effects of 5 days post-mortem storage at 1 and $18{ }^{\circ} \mathrm{C}$ showed temperature-dependent increase of proteolysis in heavy chain of myosin (MHC) and glycolytic enzyme glyceraldehyde-3-phosphate dehydrogenase (G3PD) on sea bass muscle [53]. All these gel-based proteomic studies cannot be considered as high-throughput techniques but Salem and co-workers [15] were able to characterize the proteomic profile in degenerating muscle of rainbow trout during the female reproductive cycle using a LC/MS-based label-free protein quantification method without any previous separation by $1-\mathrm{DE}$ or 2 -DE. The authors were able to identify 146 proteins that significantly changed in atrophying muscles, namely a decreased abundance of proteins belonging to anaerobic respiration, biosynthesis, monooxygenases, follistatins, and myogenin, as well as growth hormone, interleukin-1 and estrogen receptors. In contrast, proteins of MAPK/ERK kinase, glutamine synthetase, transcription factors, Stat3, JunB, Id2, and NFkap$\mathrm{paB}$ inhibitor, were greater in atrophying muscle.

Another aspect of the food quality in which foodomics has a particular interest is the development of the so-called functional food [27]. The enrichment of biologically active proteins and peptides in food products can enhance their nutritional value and satisfy the demand of customers who desire a daily healthcare without the additional intake of pharmaceutical products.

The identification of potential functional food proteins have been accomplished by Sanmartin and colleagues [54] through the proteomic study of canned and fresh tuna byproducts during their processing. This investigation enabled the identification of by-products from sarcoplasmatic and myofibrillar fractions, combining the research of peptide mass fingerprint by MALDI-TOF, with the peptide fragments fingerprinting by MALDI LIFT-TOF. The authors identified myoglobin and energy production enzymes from the sarcoplasmic fraction whereas proteins like actin, tropomyosin, myosin and an isoform of creatine kinase from the myofibrillar fraction. Proteins such as tropomyosin and haemoglobin were identified in the heat-treatment material discarded from the canning industry.

\subsection{Peptidomics and Peptide Biomarkers}

Food peptidomics and the characterization of the whole peptidome in food products or raw materials is an emerging field in food quality studies. Peptides dynamically change in food during proteolysis induced by technological treatments and interactions with other components; therefore their study can give useful information about origin, evolution, impact on sensorial properties, beneficial or adverse effects on human health [55] that can guide industrial processes or improve supply chain management.

The term "peptidomics" may refer to the study of naturally occurring peptides or to the peptidomics approach to protein analysis [56]. Therefore, there is a subtle distinction between the so-called shotgun proteomics, where proteins after digestion generate peptides suitable for MS analysis, and peptidomics which partially covers the same approach and methodologies as proteomics [55, 57]. In this context, we also include the research directed to discover peptides as specific biomarker in peptidomics although they are not strictly related to the usual definition.

Peptides, especially for MS- based techniques, are by far better analytical targets than the parent proteins. In fact, especially short peptides containing two or three amino acids, are usually better absorbed than the larger ones. Such fragments occur in protein sequences with relatively high probability and can play a key role in bioactive compounds through their peptide chain length [57].

A high-throughput strategy directed at fish authentication, was able to discover species-specific peptide biomark- 
ers of all commercial fish species belonging to the Merluccidae family, using high-intensity focused ultrasound (HIFU) tryptic digestion and selected MS/MS ion monitoring [16]. The unequivocal identification of these closely related fish species in any seafood, including processed and precooked products, was performed in less than 2 hours due to the fast HIFU application (2 minutes) to in-solution tryptic digestion that achieves an efficiency and similar reproducibility to that, obtained by traditional overnight protocols [58].

A similar strategy for the fast identification of seafood species, closely related to Decapoda shrimps, was developed by Ortea and colleagues [59]. They discovered speciesspecific peptides through the selected MS/MS ion monitoring (SMIM), the most suitable ion-trap scanning method for the detection and quantification of peptides previously sequenced by MS from complex samples.

The quality of fish products might be altered during processing and storage. For instance, nonenzymatic posttranslational modifications (nePTM) mainly caused by oxidation and by nonenzymatic reaction of sugars with amino acid side chains, significantly affect the sensorial and nutritional quality of fishery products [14].

Several publications reported nePTM in food like milk after heating or meat affected by lipoxidation but the structures and modification sites of nePTMs in processed food like seafood are largely unknown [60].

Proteolytic peptides generated from foodstuffs are also molecular targets to distinguish fresh from cold-stored materials, in order to assess the fraudulent use of prohibited refrigerated or frozen ingredients [55].The effects of ice storage and cooking in rainbow trout muscle has been analysed by Bauchart and colleagues [61] by peptidomics. The MS results showed that 6 days of ice storage and cooking conditions did not have an effect on the concentration of the identified low molecular weight peptides $(<5 \mathrm{KDa})$. However, a number of unidentified peptide did show a consistent increase due to storage and cooking. The identification of these peptides would provide a method of differentiating fresh from frozen rainbow trout products. Future studies could extend this would to other fishery products.

Some peptides found in fish products have been shown to prevent hypertension by inhibiting angiotensin-converting enzyme (ACE) or displaying antihypertensive, antioxidant, antimicrobial and antiproliferative effects [62]. ACE inhibitor peptides from fish sources were first identified in sardine muscle over twenty years ago [63] Since then ACEinhibitory peptides have been found in various fish species, including shellfish, tuna, bonito, salmon and sardine [62].

Potential valuable bioactive peptides (i.e. antimicrobial, bioactive collagen peptides and antihypertensive peptides) from sarcoplasmic proteome of 15 commercial fish species were predicted after an in silico simulated human gastrointestinal digestion [64]. Although further studies are needed to confirm these results, the discovery of potential health benefits related to these bioactive peptides could interest the market for functional food commercialization. This MS-based study underlined how the appropriate use of bioinformatic tools can speed up the research into potential target peptides without incurring major costs [65].
Specific peptides obtained after enzymatic digestion of fish proteins can be utilized to enhance salt taste in food, namely a series of arginyl dipeptides, with RP, RA, AR, RG, RS, RV, VR, and RM having been found to be the most active, as well as L-arginine as salt taste enhancing molecules in fish protamine digests and fermented fish sauces [66]. In this recent study, the authors applied chromatography techniques coupled to LC-MS/MS analysis utilizing "sensomics", a new research area which aims to characterize the most intense taste-active metabolites in fresh and processed foods.

\section{PROTEOMIC SAFETY BIOMARKERS IN FISH- ERY PRODUCTS}

Consumer preferences range from fresh seafood products that can be eaten raw or minimally processed, to those specially prepared such as salted, smoked, cured or canned [67].

Although seafood consumption is recommended as a part of a healthy diet, hazards caused by naturally occurring toxins, environmental contaminants and microbes can cause public health concerns.

The challenge for seafood safety is using advanced and robust technology tools to detect very low concentrations of toxins, harmful compounds, micro-organisms, allergens and/or eventual food compositional changes from various stages of food processing, packaging, and storage, especially from long distance shipments.

The Food and Drug Administration (FDA) has issued industry guidelines aiming to establish procedures for the safe processing and importing of fish and fishery products based on the hazard analysis and critical control points (HACCP) approach [68] as numerous foodborne illnesses still exist in developing and developed countries.

\subsection{Toxins and Other Environmental Contaminants De- tection}

The consumption of shellfish contaminated by algal toxins can cause several major human toxic syndromes. The large-scale ecological changes from anthropogenic activities, especially increased eutrophication, marine transport, aquaculture, and global climate change could be indirectly related with the increase of human toxicity by contaminated shellfish consumption. Therefore, new efforts have been devoted to improve methods for toxin detection in different matrices that could assess the presence of those compounds in food and prevent human exposure to shellfish toxins.

The frequency of occurrence and intensity of harmful algal blooms has increased on a global scale in recent years. Fisheries and aquaculture industries are especially susceptible to contamination from harmful algal blooms and marine biotoxins. These algae-related poisoning can be classified in clinical types: paralytic shellfish poisoning, diarrheic shellfish poisoning and amnesic shellfish poisoning are among the most common. Biotoxins such as okadaic acid, dinophysistoxins, pectenotoxins, yessotoxins, gymnodimine, spirolides, azaspiracids and azaspiracid analogs, domoic acid, mycrocystins and other cyanotoxins, have been successfully detected by MS-based techniques [69-75].

The biotoxin okadaic acid and developing methods for the identification has attracted a lot of interest during the last 
two decades as it represents the most predominant diarrheic shellfish poisoning biotoxin in the European coastal waters. The traditional strategy for biomonitoring this compound in the marine environment has been based on regular screening of the waters, in order to detect potential toxic phytoplankton, especially during Dinophysis acuminata and Protoceratium reticulatum blooms. Later, a solid phase adsorption toxin tracking method, SPATT, was developed based on the use of passive samplers. MacKenzie et al. [69] reported this biomonitoring strategy as an alternative early warning method for predicting contamination events and predicting the net accumulation of polyether toxins by mussels. The advantage of this system is that it simplifies the identification of the toxins by only having to monitor the parent compound and not the toxin analogues produced by in vivo biotransformation in shellfish tissues.

However, recently, several chromatographic methods coupled to tandem mass spectrometry (LC-MS/MS) have been developed for the determination of the main groups of marine lipophilic toxins (okadaic acid and dinophysistoxins, pectenotoxins, azaspiracids, yessotoxins, gymnodimine and spirolides). Garcia-Altares et al. [70] compared two quantitative methodologies, the external standard calibration and the matrix-matched standard calibration, to define the most suitable conditions as stated by the European Union Reference Laboratory for Marine Biotoxins (EURLMB). Increasing the sample throughput should be an aim in the development of these methodologies. Therefore, the authors recommended alkaline conditions with the external standard calibration to accomplish the analysis of all toxins in a single run. Another goal is identifying different biotoxin analogs. At least eleven analogs of azaspiracids have been described. Applying the state-of-the-art techniques including ultra-performance liquid chromatography and tandem mass spectrometry (MS/MS), all of those compounds have been identified in blue mussel [71]. However, it is expectable that the newly discovered azaspiracid analogs were present at low concentrations in the shellfish and it is probably safe to assume, at these concentrations, they do not pose a risk to the shellfish consumer [71].

The gymnodimines is an emerging group of marine toxins, although they have not yet been linked to incidents of human poisoning. They are a subclass of lipophilic fastacting toxins that belong to the cyclic imine group. However, the presence of a range of acyl ester derivatives of gymnodimines has been detected for the first time in shellfish samples from Tunisia. For the detection, a series of mass spectrometric experiments involving precursor and product ion scans, selected reaction monitoring (SRM), and highresolution MS were performed [72].

A potent neurotoxin responsible for the syndrome amnesic shellfish poisoning, domoic acid, was detected for the first time in shellfish harvested in Ireland in 1999. Different methodologies have been developed since then to identify and quantify this compound either based on liquid chromatography and solid-phase extraction with strong anion exchange cartridges or by using an ultraviolet photodiode array absorbance detector coupled to multiple tandem mass spectrometry (LC-MSn) [73]. The amount in mussels, oysters and razor clams were within the EU guideline limits for the sale of shellfish $(20 \mu \mathrm{g} / \mathrm{g})$.
Microcystins are cyanotoxins that occur in ground water and also pose a potential health risk. Microcystin-LR (microcystin-leucine-arginine) is suspected of being a tumour promoter and to cause hepatic dysfunction [76, 77]. A recent study has evaluated the effects of this cyanotoxin on liver from Medaka fish (Oryzias latipes). Applying an iTRAQ labeled quantitative proteomic approach, more than 300 proteins showed statistically significant variations and most of them were implicated in the translation, maturation or degradation of proteins or in lipid metabolism and detoxification [74]. In particular, the authors underlined the deregulation of several apolipoproteins that indicates a possible alteration of chylomicron-mediated transport. Their accumulation in Medaka fish hepatocytes can be due to the disruption of several cytoskeleton components (i.e. actin network, microtubules and intermediate filaments) observed after microcystin-LR exposure. The authors, for the first time, by using this high-throughput technique, were able to identify 15 proteins (i.e. aminocarboxymuconate semialdehyde decarboxylase, uricase, mortalin, calreticulin, glutaredoxin, warm temperature-acclimation-related-65-kDa-protein, homogentisate-1,2dioxygenase, kininogen, cathepsin, 17-b-Hydroxysteroid dehydrogenase 4 like, Acyl-coenzyme A binding protein, Acyl-coenzyme A oxidase 3,14KDa apolipoprotein, apolipoprotein A-IV/V, apolipoprotein E) not evidenced in similar previous gel-based proteomic studies and by genomics[74].

A peptidomic approach aimed at characterising and quantify the peptide cyanotoxins produced in two Italian lakes, Averno and Albano, has been carried out [75]. The procedure was based on matrix-assisted laser desorption/ionisation time-of-flight mass spectrometry (MALDI-TOF-MS) analysis for rapid detection and profiling of the peptide mixture, combined with liquid chromatography/electrospray ionisation quadrupole time-of-flight tandem mass spectrometry (LC/ESI-Q-TOF-MS/MS) which provided unambiguous structural identification of the main compounds, as well as accurate quantitative analysis of microcystins. Work is in progress to apply this analytical strategy to other classes of cyanotoxins, to obtain new information about cyanotoxins contaminating Italian lakes. The same methodology is being currently extended to the analysis of animal tissues (fish, crustaceans, mussels) from contaminated freshwaters, representing a possible risk of poisoning for humans [75].

Other environmental contaminants like toxic elements (e.g. $\mathrm{Hg}, \mathrm{Cd}, \mathrm{Pb}$ and $\mathrm{As}$ ), radionuclides, polycyclic aromatic hydrocarbons (PAHs), polychloro biphenyl (PCB) and dioxins in fish and shellfish not only can affect the health and quality of the farmed products but can also constitute a serious health hazard for the consumers.

Classical analytical techniques are typically used to detect most of these environmental contaminants and some of them can be technically difficult to detect. Biotransformation processes may occur, producing by-products more hazardous than the parent molecules that can be under the instrument detection-limits or under the limit set by the legislative authority. In addition, the bioaccessibility of environmental compounds can be affected by cooking and processing and cause repercussion on human health.

For example, seafood contaminated with some type of arsenic containing compounds can potentially cause greater 
risks to human health after cooking. Samples of sole, dory, hake, and sardine containing arsenobetaine (AB), virtually non toxic, after cooking processes (i.e. baking, frying, and grilling) at various temperatures produced tetramethylarsonium ions (TMA+), which are toxic, possibly due to the decarboxylation of $\mathrm{AB}$ to (TMA+) [78].

Another interesting study showed the carcinogenic risk associated with the intake of PAHs through consumption of edible marine species (i.e. sardine, tuna, anchovy, mackerel, swordfish, salmon, hake, red mullet, sole, cuttlefish, squid, clam, mussel, and shrimp) by Catalonians, in Spain, belonging to eight age and sex groups [79]. Mussel, clam, and shrimp had the highest PAH concentrations whilst sole, cuttlefish and squid had the lowest mean concentration. Women and female children showed highest PAH intake but female adolescents and seniors showed the lowest ones.

Consumer concern has also emerged over PCB and dioxins that are found in fish rich in fatty acids. In particular prenatal exposure of these compounds may affect subsequent cognitive performance of pre-school children [80].

In this context, the integration of toxicology with highthroughput transcriptomics, proteomics and metabolomics can be extremely useful in providing an early and more sensitive detection of toxicity, a better understanding of the mechanism of toxicity, and a prediction of toxicity of unknown compounds in organisms [81] like fish and shellfish. This discipline, known as toxicogenomics, has not been applied for high-throughput screenings in fishery products yet; its application has only recently been performed in Atlantic cod (Gadus morhua) liver, after in vivo methylmercury exposure [82]. Numerous genes coding for enzymes involved in metabolism of amino acids, fatty acids and glucose were found differentially regulated and can be potential candidates for monitoring environmental $\mathrm{MeHg}$ pollution. However, their validation by proteomics is needed to confirm the pathways suggested by transcriptomic analysis.

Environmental contaminants in fish and shellfish that can be toxic for human consumption have been analysed in several gel-based proteomic studies. They reported changes in the proteome of juvenile Atlantic cod (Gadus morhua) [83] of mussel Mytilus edulis exposed to PAH and alkyl phenols [84], to PCB and PAH ([85]), in the clam Chamaelea galina exposed to PCB [86], to As [87] or the clam Ruditapes decussatus exposed to Cd [88].

In general these studies evidenced an altered metabolism of amino acids and fatty acids, increase of glycolysis, oxidative stress, detoxification mechanisms and degradation of structural proteins that in turn have negative effects on the product safety and quality $[10,14]$.

The only gel-free proteomics approach that has been used in mussels Mytilus edulis exposed to environmental contaminants, oil spiked with PAH and alkylphenols, employed a protein-chip array combined with surface-enhanced laser desorption/ionization time-of-flight MS (SELDI TOF MS) [89]. Although this study is able to identify a specific pollutant when its identity is not known, the missing protein identification excludes the possibility to understand the potential mechanisms of actions.
In the future, high-throughput targeted proteomics, in fishery products, could be applied to promptly monitor the identified protein indicators of exposure to environmental contaminants. No proteomic studies have so far focused on the effects of environmental compounds in freshwater fishery products or in general processed and cooked fish and shellfish have been addressed; these aspects should also be evaluated in future studies to optimize the entire production chain of fishery products ensuring safety and quality to consumers.

\subsection{Bacteria Detection}

The most common pathogens such as Campylobacter jejuni, Staphylococcus aureus, Listeria monocytogenes, some Salmonella spp., certain Bacillus strains and Escherichia coli O157:H7, have been found in fresh/raw fishery and seafood products, causing continual threats to human health [90].

Nonetheless, Vibrio parahaemolyticus is the leading causative agent of bacterial seafood-borne gastroenteritis in the United States [91].

A recent study showed imported seafood from 12 countries had contamination rates for target bacteria ranging from $0.6 \%$ for C. jejuni and Salmonella to $9.4 \%$ for E. coli, suggesting the need of further large-scale studies to warrant food safety hazards [92].

In this context, numerous scientists recognized that largescale utilization of MS-based proteomics could sensitively accelerate the detection time of potential hazard in seafood through both the direct identification and quantitation of pathogens proteins or relative protein biomarkers, previously successfully tested for species and strains of specific bacteria. However, there are few investigations that follow changes of the proteome of contaminating bacteria during food processing and equipment sanitation.

The Bacterium C. jejuni proteome was analysed for the first time by Cordwell and his colleagues [93], through the combination of the traditional 2-DE and MudPIT analysis identifying 453 unique proteins, of which 187 were membrane proteins, and a further 108 were predicted to contain at least one transmembrane-spanning region, usually hydrophobic proteins difficult to separate by 2-DE.

An important step towards research by automated detection of microbial contamination was achieved by Fagerquist and colleagues [94], who developed a web-based software for rapid top-down proteomic identification of small proteins (and their source bacterial microorganisms) from analysis of MS-MS fragment ions of intact bacterial proteins generated using MALDI-TOFTOFMS. A simple peak-matching algorithm was used to score and rank identifications of proteins and microorganisms (e.g. some Campylobacter and Escherichia coli strains) comparing MS-MS fragment ions to in silico fragment ions generated from bacterial protein sequences derived from genomic databases.

Technological food preservation techniques such as high hydrostatic pressure (HHP) or vacuum-packaging, although inhibit the growth of microorganisms, do not exclude the survival of some bacteria like Bacillus cereus or Streptococcus parauberis. Martinez-Gomariz and colleagues [95] analysed changes in the proteome of $B$. cereus during HHP 
treatment and found quantitative differences of proteins involved in nucleotide metabolic process, carbohydrate catabolism, transport, refolding, amino acid biosynthesis and ciliary/flagellar motility. This proteomic study highlighted as a specific HHP treatment at 700MP may reduce the virulence and protective response against oxidative stress in these bacteria preventing food borne illnesses.

Another recent proteomic success directed towards a rapid pathogen and spoilage bacteria identification method in food products is the first report of $S$. parauberis in seafood and in vacuum-packed food products through the identification of five peaks in the range of $2200-6000 \mathrm{~m} / \mathrm{z}$ specific to this bacteria species by MALDI-TOF MS [96]. In particular, the authors analysed these bacteria species from a commercial surimi-based product subjected to vacuum packaging and refrigeration.

The same MALDI-TOF MS fingerprinting approach was previously used by Böhme and colleagues [97-98] to differentiate several gram-negative and gram-positive bacteria (e.g. Bacillus, Listeria, Clostridium, Staphylococcus spp.) in seafood.

Although these authors mainly isolated most of the bacteria from collected cultures, specific gram-negative strains such as Serratia marcescens, Stenotrophomonas maltophilia and Pseudomonas fragi were selected from processed seafood, fresh and frozen tuna Thunnus alalunga and from sardins, respectively [97], whilst the gram-positive strains Staphylococcus aureus, Carnobacterium maltaromaticum, C. Maltaromaticum, Bacillus subtilis, B. licheniformis and B. Megaterium were selected strains were from a shelf-life study of vacuum-packed seafood products that were subjected to a mild heat treatment and stored refrigerated [98].

Another MALDI-TOF MS-based strategy but on intact bacterial cells from slants and grown in laboratory conditions was developed for a rapid and accurate identification of 24 different foodborne pathogens and food spoilage bacteria such as Salmonella, Escherichia, Yersinia, Staphilococcus or Listeria [99].

A rapid identification of $V$. parahaemolyticus from different geographical locations and at different time was achieved by a whole-cell MALDI-TOF MS method, allowing the distinction of the closely related strains $V$. alginolyticus, $V$. harveyi and $V$. cambelli [91]. V. parahaemolyticus was isolated from sediment, water, and oyster samples from Georgia, Florida, and North Carolina while the other strains were grown in broth at laboratory conditions. These latter two MS-based studies show the advantage in using intact cells skipping analysis steps such as cell lysis and/or protein digestion, which affect the speed, logistic and expenses of the analysis.

Despite the several studies applying high-throughput proteomic techniques in food and seafood products, as described in this review, most of them have missing useful information about species.

\subsection{Allergen Detection}

The detection of food allergens is a hot topic in food safety because of the increasing susceptibility of individuals who must avoid the consumption of these allergens, even in small quantities, while a complete cure for these reactions is not yet available [27].

Most allergens are usually low molecular weight proteins or glycoproteins (Mw 10,000-70,000 KDa) [100] and their traditional detection in food is mainly based on the use of specific antibodies or DNA primers limited by their availability and achievable detection limit [101]. Allergens often exhibit specific biochemical and physiochemical properties (e.g. thermal stability and resistance to proteolysis) depending on their binding to metals ions, lipid, steroids or proteins and their study has been favoured by MS application [102].

A powerful tool like proteomics, and especially the use of MS, can be an unambiguous and sensitive alternative approach for food allergens detection and generally all proteomic strategies used for a detailed characterization of these compounds is referred as "allergenomics" [103].

In seafood products, the major fish allergens are parvalbumins beta (ß-PRVBs), a calcium-binding protein with low molecular weight $(\sim 10-12 \mathrm{KDa})$, with acidic pI, present in high amounts in the sarcoplasmic fraction of white muscles of fish and resistant to heat and digestive enzymes [104, 105].

Allergenomic studies in seafood products have been only sparingly applied using SDS-PAGE and immunoblotting [105] or these techniques combined with MS [106, 107]. Other scientists investigated the allergenic mechanisms of the parvalbumin fraction with myofibrillar protein fraction using crystallography [108] or immunological tools [109] which are not proteomic techniques in sensu stricto [110].

Clinical cross-reactivity of parvalbumins from different fish species $[111,112]$ and their characterization in different species belonging to Merluccidae family were evaluated by 2DE and MALDI-TOF MS [113]. However, the authors were able to recognize clearly species-specific differences in the peptides pattern of the parvalbumin fractions only through MALDI-TOF mass fingerprinting and subsequently to identify 25 new $\beta$-PRVBs isoforms by de novo MSsequencing in 11 species of Merluccidae through a classical bottom-up proteomic approach using Fourier-transform ioncyclotron resonance mass spectrometry (FTICR-MS) for an accurate mass measurement of intact proteins and selected MS/MS ion monitoring (SMIM) of peptide mass gaps [114]. Although these studies have been based on the preliminary use of 2DE, Carrera and colleagues [17] recently developed a new shotgun proteomic strategy more suitable for a rapid detection of fish $\beta-P R V B s$ in any food product in less than 2 hours and its validity in commercial sea-foodstuffs were tested in processed and even battered pre-cooked products. Briefly, this targeted-driven methodology is based on the fast purification of parvalbumins by heat treatment, accelerated in-solution protein digestion by high-intensity focused ultrasound (HIFU) monitoring of 19 ß-PRVBs common peptide biomarkers by SMIM in a linear ion trap (LIT) MS.

Other gel-free proteomic techniques in aquaculture organisms were used by Taka and colleagues [115] in Rana catesbeiana for the characterization of an allergen belonging to $\beta$-PRVBs through tandem mass spectrometry in combination with amino acid analysis and peptide sequencing after Arg-C and V(8) protease digestion. The authors recognized 
the necessity to use the combination of ESI-MS with the amino acid analysis by Edman degradation for the protein sequence identification and/or any PTM, because more than 10 years ago, when this study was published, MALDI-TOF and/or recent MS technologies were not so well known.

The main allergens in crustaceans and cephalopods are tropomyosin, a 34-38 kDa microfibrillar protein with amino acid sequence highly conserved among shellfish [116, 117], and arginine kinase [118].

Food products like crustaceans are among the most common causes of allergies $[119,120]$, but only a few proteomic studies analysed these allergens by MS, although through prior SDS-PAGE protein separations [121, 122].

Up to now the bottom-up strategy is the most widely used in allergenomics [27] although MS analyses are often performed only after tryptic digestion of proteins separated by 1 or $2 \mathrm{DE}$. These methodologies are very effective but not admissible in aquaculture, fish plants and industries that need high-throughput techniques able to monitor simultaneously several allergens and especially quantify them rapidly.

Some authors, as described above, used shotgun proteomics techniques in allergenomics but only Stevenson et al. [123] developed for the first time a gel-free, label-free quantitative proteomics approach based on peak integration and spectra counting to compare versus protein standards in seed allergens. In the future a similar methodology could be applied in aquaculture products even if it is crucial the need of appropriate reference materials for allergens and more validations.

\section{CONCLUSIONS AND FUTURE PERSPECTIVES}

Nowadays, it is well known that a daily balanced diet based on proteins combined with other nutrients is important for a healthy longer life. In particular, fish products are an excellent source of proteins with recognized benefits for some disease prevention, and are rapidly arousing a growing interest by the consumers.

In fact, most of the fish products, compared to other protein sources like meat or poultry, are lower in saturated fat and cholesterol. Fish industries and aquaculture systems are therefore called upon to respond to this demand for increasing food production, though without omitting the careful diagnostic analysis that guarantees high safety and quality criteria for demanding consumers.

It is clear that advanced technological development is one of the key factors for the success of large-scale industrial aquaculture production systems. Although this type of expansion often requires an important initial economic investment, through an appropriate business organization, it is possible to gain excellent economic returns.

High-throughput proteomic technology allows a better in-process control than traditional diagnostic methodologies enabling a rapid characterization of batch-to-batch variations in fisheries and aquaculture food products.

Such methodologies can then be used to optimize the entire production chain from the water to the table, from selection and breeding to processing and cooking [14].
This review is an overview of the MS-based proteomics approaches employed until now as sensitive and promising techniques for traceability, authenticity, biological and microbial safety and quality control of seafood and fish products. To date, although these high-throughput proteomic applications and the research in technical improvements in the speed and sensitivity of the methodologies are increasing, there are still some restrictions for seafood and fish products due to their limited available genomes and proteomes in databases. For this reason, to enhance the probability for protein-identification, 2-DE-based proteomics still remains the most widely used approach in proteomic research in seafood and aquaculture, even if it is time-consuming. However, the increased capabilities of LC, with longer columns, and $\mathrm{CE}$ with MS/MS capabilities will increase the sequence data available in the proteomic databases.

The combination of consecutive proteomic strategies, discovery and target-driven phases, can be a reasonable alternative to identify and characterize several peptide and protein biomarkers, analysable by MS, thus allowing a rapid screening for quality and safety control for the seafood industries.

The first phase requiring the combination of 2-DE and MS, could still be the discovery method, carried out in research centres, while the high throughput target-driven phase could be used for routine screening in the fishery and seafood industries, during specific steps, to ensure quality and safety throughout the production process.

In fact, future trends are oriented towards protein or peptide array technologies, lab-on-chips devices and biosensors, high-throughput measurements largely driven by MS-derived information that can simultaneously determine presence/absence of specific protein or peptide biomarkers and their amount, ensuring a more rapid and accurate assessment of seafood and fish products in food control laboratories.

\section{CONFLICT OF INTEREST}

The author(s) confirm that this article content has no conflicts of interest.

\section{ACKNOWLEDGEMENT}

ST was supported by STSM from COST ACTION 1002 for the travel to University of Glasgow. SC was supported by grants from the Swedish Research Council-Natural Science (VR-NT), Carl Trygger Foundation, Oscar and Lilli Lamms Minne Foundation, Längmanska kulturfonden, Lars Hiertas Minne foundation, IKERBASQUE, Basque Foundation for science, LiU support, LiU Cancer, SSF, ALF and Ångpanneförening research foundation.

\section{REFERENCES}

[1] Grunert, K.G. Food quality and safety: consumer perception and demand. Eur. Rev. Agric. Econ., 2005, 32, 369-391.

[2] Food and Agriculture Organization of the United Nations.; World Health Organization. Report of the Joint FAO/WHO Expert Consultation on the Risks and Benefits of Fish Consumption. http://www.fao.org/docrep/014/ba0136e/ba0136e00.pdf:(Accessed January 25-29, 2010).

[3] Samuel-Fitwi, B.; Wuertz, S.; Schroeder, J.P.; Schulz, C. Sustainability assessment tools to support aquaculture development. J. Clean. Prod., 2012, 32, 183-192. 
[4] Natale, F.; Hofherr, J.; Fiore, G.; Virtanen, J. Interactions between aquaculture and fisheries. Mar. Policy, 2013, 38, 205-213.

[5] Bostock, J.; McAndrew, B.; Richards, R.; Jauncey, K.; Telfer, T.; Lorenzen, K.; Little, D.; Ross, L.; Handisyde, N.; Gatward, I.; Corner, R. Aquaculture: global status and trends. Philos. Trans. R. Soc. Lond. B. Biol. Sci., 2010, 365, 2897-2912.

[6] International Association for Impact Assessment. IAIA. Principle of environmental impact assessment best practice. http://www.iaia.org/publicdocuments/special-

publications/Principles\%20of\%20IA_web.pdf (Accessed 1999).

[7] Food and Agriculture Organization of the United Nations.; FAO Fisheries and Aquaculture Dept. Aquaculture Management and Conservation Service. Environmental impact assessment and monitoring in aquaculture: requirements, practices, effectiveness and improvements. ftp://ftp.fao.org/docrep/fao/012/i0970e/i0970e.pdf. (Accessed, 2009).

[8] Food and Agriculture Organization of the United Nations. Understanding and applying risk analysis in aquaculture: a manual for decision-makers. http://www.fao.org/docrep/012/11136e/i1136e.pdf (Accessed, 2009).

[9] Rodrigues, P.M.; Silva, T.S.; Dias, J.; Jessen, F. Proteomics in aquaculture: Applications and trends. J. Proteomics, 2012, 75, 4325-4345.

[10] Campos, A.; Tedesco, S.; Vasconcelos, V.; Cristobal, S. Proteomic research in bivalves: Towards the identification of molecular markers of aquatic pollution. J. Proteomics, 2012, 75, 4346-4359.

[11] Martyniuk, C.J.; Alvarez, S.; McClung, S.; Villeneuve, D.L.; Ankley, G.T.; Denslow, N.D. Quantitative proteomic profiles of androgen receptor signaling in the liver of fathead minnows (Pimephales promelas). J. Proteome Res., 2009, 8, 2186-2200.

[12] D'Alessandro, A.; Zolla, L. We are what we eat: food safety and proteomics. J. Proteome Res., 2011, 11, 26-36.

[13] Pedreschi, R.; Hertog, M.; Lilley, K.S.; Nicolaï, B. Proteomics for the food industry: opportunities and challenges. Crit. Rev. Food Sci. Nutr., 2010, 50, 680-692.

[14] Piñeiro, C.; Martinez, I. Evaluation of Fish Quality and Safety by Proteomics Techniques. In Proteomics in Foods, Toldrá, F.; Nollet, L.M.L., Eds. Springer US: 2013; vol. 2, pp. 161-180.

[15] Salem, M.; Kenney, P.B.; Rexroad I, C.E.; Yao, J. Proteomic signature of muscle atrophy in rainbow trout. J.Proteomics, 2010, 73, 778-789.

[16] Carrera, M.N.; Cañas, B.; López-Ferrer, D.; Piñeiro, C.; Vázquez, J.S.; Gallardo, J.M. Fast monitoring of species-specific peptide biomarkers using high-intensity-focused-ultrasound-assisted tryptic digestion and selected MS/MS ion monitoring. Anal. Chem., 2011, 83, 5688-5695.

[17] Carrera, M.; Cañas, B.; Gallardo, J.M. Rapid direct detection of the major fish allergen, parvalbumin, by selected MS/MS ion monitoring mass spectrometry. J.Proteomics, 2012, 75, 3211-3220.

[18] Capozzi, F.; Bordoni, A. Foodomics: a new comprehensive approach to food and nutrition. Genes Nutr., 2012, 8, 1-4.

[19] Cerdà, J.; Manchado, M. Advances in genomics for flatfish aquaculture. Genes Nutr., 2012, 8, 1-13.

[20] Zhang, G.; Fang, X.; Guo, X.; Li, L.; Luo, R.; Xu, F.; Yang, P.; Zhang, L.; Wang, X.; Qi, H.; Xiong, Z.; Que, H.; Xie, Y.; Holland, P.W.H.; Paps, J.; Zhu, Y.; Wu, F.; Chen, Y.; Wang, J.; Peng, C.; Meng, J.; Yang, L.; Liu, J.; Wen, B.; Zhang, N.; Huang, Z.; Zhu, Q.; Feng, Y.; Mount, A.; Hedgecock, D.; Xu, Z.; Liu, Y.; DomazetLoso, T.; Du, Y.; Sun, X.; Zhang, S.; Liu, B.; Cheng, P.; Jiang, X.; Li, J.; Fan, D.; Wang, W.; Fu, W.; Wang, T.; Wang, B.; Zhang, J.; Peng, Z.; Li, Y.; Li, N.; Wang, J.; Chen, M.; He, Y.; Tan, F.; Song, X.; Zheng, Q.; Huang, R.; Yang, H.; Du, X.; Chen, L.; Yang, M.; Gaffney, P.M.; Wang, S.; Luo, L.; She, Z.; Ming, Y.; Huang, W.; Zhang, S.; Huang, B.; Zhang, Y.; Qu, T.; Ni, P.; Miao, G.; Wang, J.; Wang, Q.; Steinberg, C. E. W.; Wang, H.; Li, N.; Qian, L.; Zhang, G.; Li, Y.; Yang, H.; Liu, X.; Wang, J.; Yin, Y.; Wang, J. The oyster genome reveals stress adaptation and complexity of shell formation. Nature, 2012, 490, 49-54.

[21] Green-Petersen, D.; Nielsen, J.; Hyldig, G. A Model for Communication of Sensory Quality in the Seafood Processing Chain. Crit. Rev. Food Sci. Nutr., 2011, 52, 443-447.

[22] Mamone, G.; Picariello, G.; Caira, S.; Addeo, F.; Ferranti, P. Analysis of food proteins and peptides by mass spectrometry-based techniques. J. Chromatogr. A, 2009, 1216, 7130-7142.

[23] Han, X.; Aslanian, A.; Yates I, J. R., Mass spectrometry for proteomics. Curr. Opin. Chem. Biol., 2008, 12, 483-490.
[24] Jorgenson, J.W.; Lukacs, K.D. Zone Electrophoresis in opentubular glass-capillaries. Anal. Chem., 1981, 53, 1298-1302.

[25] Recio, I.; Ramos, M.; López-Fandiño, R. Capillary electrophoresis for the analysis of food proteins of animal origin. Electrophoresis, 2001, 22, 1489-1502.

[26] Smith, R.D.; Olivares, J.A.; Nguyen, N.T.; Udseth, H.R. Capillary zone electrophoresis-mass spectrometry using an electrospray ionization interface. Anal. Chem., 1988, 60, 436-441.

[27] Herrero, M.; Simó, C.; García-Cañas, V.; Ibáñez, E.; Cifuentes, A. Foodomics: MS-based strategies in modern food science and nutrition. Mass Spectrom. Rev., 2012, 31, 49-69.

[28] Ravelo-Pérez, L.M.; Asensio-Ramos, M.; Hernández-Borges, J.; Rodríguez-Delgado, M.Á. Recent food safety and food quality applications of CE-MS. Electrophoresis, 2009, 30, 1624-1646.

[29] Dawson, J.; Walters, M.; Delles, C.; Mischak, H.; Mullen, W. Urinary proteomics to support diagnosis of stroke. PloS One, 2012, 7, e35879.

[30] Mullen, W.; Delles, C.; Mischak, H.; EuroKUP COST action.Urinary proteomics in the assessment of chronic kidney disease. Curr. Opin. Nephrol. Hypertens., 2011, 20, 654-661.

[31] Delles, C.; Schiffer, E.; von zur Muhlen, C.; Peter, K.; Rossing, P.; Parving, H.H.; Dymott, J.A.; Neisius, U.; Zimmerli, L.U.; SnellBergeon, J.K.; Maahs, D.M.; Schmieder, R.E.; Mischak, H.; Dominiczak, A.F. Urinary proteomic diagnosis of coronary artery disease: identification and clinical validation in 623 individuals. $J$. Hypertens., 2010, 28, 2316-2322.

[32] Müller, L.; Barták, P.; Bednáŕ, P.; Fryšová, I.; Ševčík, J.; Lemr, K. Capillary electrophoresis-mass spectrometry - a fast and reliable tool for the monitoring of milk adulteration. Electrophoresis, 2008, 29, 2088-2093.

[33] Simó, C.; Barbas, C.; Cifuentes, A. Capillary electrophoresis-mass spectrometry in food analysis. Electrophoresis, 2005, 26, 13061318.

[34] Haselberg, R.; Ratnayake, C.K.; de Jong, G.J.; Somsen, G.W. Performance of a sheathless porous tip sprayer for capillary electrophoresis-electrospray ionization-mass spectrometry of intact proteins. J. Chromatogr. A, 2010, 1217, 7605-7611.

[35] Wolters, D.A.; Washburn, M.P.; Yates, J.R. An automated multidimensional protein identification technology for shotgun proteomics. Anal. Chem., 2001, 73, 5683-5690.

[36] Thakur, S.S.; Geiger, T.; Chatterjee, B.; Bandilla, P.; Frohlich, F.; Cox, J.; Mann, M. Deep and highly sensitive proteome coverage by LC-MS/MS without prefractionation. Mol. Cell. Proteomics, 2011, 10, M110.003699.

[37] Mullen, W.; Albalat, A.; Gonzalez, J.; Zerefos, P.; Siwy, J.; Franke, J.; Mischak, H. Performance of different separation methods interfaced in the same MS-reflection TOF detector: A comparison of performance between CE versus HPLC for biomarker analysis. Electrophoresis, 2012, 33, 567-574.

[38] Wojcik, R.; Dada, O.O.; Sadilek, M.; Dovichi, N.J. Simplified capillary electrophoresis nanospray sheath-flow interface for high efficiency and sensitive peptide analysis. Rapid Commun. Mass. Spectrom., 2010, 24, 2554-2560.

[39] Sun, L.L.; Zhu, G.J.; Li, Y.H.; Wojcik, R.; Yang, P.; Dovichi, N.J. CZE-ESI-MS/MS system for analysis of subnanogram amounts of tryptic digests of a cellular homogenate. Proteomics, 2012, 12, 3013-3019.

[40] Stalmach, A.; Albalat, A.; Mullen, W.; Mischak, H. Recent advances in capillary electrophoresis coupled to mass spectrometry for clinical proteomic applications. Electrophoresis, 2013, 34, 1452-1464..

[41] Martinez, I.; Aursand, M.; Erikson, U.; Singstad, T.E.; Veliyulin, E.; van der Zwaag, C. Destructive and non-destructive analytical techniques for authentication and composition analyses of foodstuffs. Trends Food Sci. Tech., 2003, 14, 489-498.

[42] Asensio, L.; González, I.; Rodríguez, M.A.; Mayoral, B.; LópezCalleja, I.; Hernández, P.E.; García, T.; Martín, R. Identification of grouper (Epinephelus guaza), Wreck Fish (Polyprion americanus), and Nile Perch (Lates niloticus) fillets by polyclonal antibodybased enzyme-linked immunosorbent assay. J. Agric. Food Chem., 2003, 51, 1169-1172.

[43] Martinez, I.; Jakobsen Friis, T. Application of proteome analysis to seafood authentication. Proteomics, 2004, 4, 347-354.

[44] Piñeiro, C.; Vázquez, J.; Marina, A.I.; Barros-Velázquez, J.; Gallardo, J.M. Characterization and partial sequencing of speciesspecific sarcoplasmic polypeptides from commercial hake species 
by mass spectrometry following two-dimensional electrophoresis. Electrophoresis, 2001, 22, 1545-1552.

[45] Mazzeo, M.F.; Giulio, B.D.; Guerriero, G.; Ciarcia, G.; Malorni, A.; Russo, G.L.; Siciliano, R.A. Fish authentication by MALDITOF mass spectrometry. J. Agric. Food Chem., 2008, 56, 1107111076 .

[46] Volta, P.; Riccardi, N.; Lauceri, R.; Tonolla, M. Discrimination of freshwater fish species by Matrix-Assisted Laser Desorption/Ionization-Time Of Flight Mass Spectrometry (MALDI-TOF MS): a pilot study. J. Limnol., 2012, 71, e17.

[47] Unseld, M.; Beyermann, B.; Brandt, P.; Hiesel, R. Identification of the Species Origin of Highly Processed Meat-Products by Mitochondrial-DNA Sequences. Pcr Meth. Appl., 1995, 4, 241-243.

[48] Nicole, S.; Negrisolo, E.; Eccher, G.; Mantovani, R.; Patarnello, T.; Erickson, D.L.; Kress, W.J.; Barcaccia, G. DNA barcoding as a reliable method for the authentication of commercial seafood products. Food Technol. Biotech., 2012, 50, 387-398.

[49] Piñeiro, C.; Barros-Velázquez, J.; Vázquez; Figueras, A. Proteomics as a tool for the investigation of seafood and other marine products. J.Proteome Res., 2002, 2, 127-135.

[50] Alomirah, H.F.; Alli, I.; Konishi, Y., Applications of mass spectrometry to food proteins and peptides. J. Chromatogr. A, 2000, 893, 1-21.

[51] Johnston, I.A. Muscle development and growth: potential implications for flesh quality in fish. Aquaculture, 1999, 177, 99115.

[52] Veiseth-Kent, E.; Grove, H.; Færgestad, E.M.; Fjæra, S.O. Changes in muscle and blood plasma proteomes of Atlantic salmon (Salmo salar) induced by crowding. Aquaculture, 2010, 309, 272-279.

[53] Terova, G.; Addis, M.F.; Preziosa, E.; Pisanu, S.; Pagnozzi, D.; Biosa, G.; Gornati, R.; Bernardini, G.; Roggio, T.; Saroglia, M. Effects of postmortem storage temperature on sea bass (Dicentrarchus labrax) muscle protein degradation: Analysis by 2D DIGE and MS. Proteomics, 2011, 11, 2901-2910.

[54] Sanmartín, E.; Arboleya, J.C.; Iloro, I.; Escuredo, K.; Elortza, F.; Moreno, F.J. Proteomic analysis of processing by-products from canned and fresh tuna: Identification of potentially functional food proteins. Food Chem., 2012, 134, 1211-1219.

[55] Picariello, G.; Mamone, G.; Addeo, F.; Ferranti, P. Novel mass spectrometry-based applications of the 'omic' sciences in food technology and biotechnology. Food Technol. Biotechnol., 2012, 50, 286-305.

[56] Soloviev, M. Peptidomics: Divide et Impera. In Peptidomics, Soloviev, M. Ed. Humana Press: 2010; vol. 615, pp. 3-9.

[57] Minkiewicz, P.; Dziuba, J.; Darewicz, M.; Iwaniak, A.; Dziuba, M.; Nalecz, D. Food peptidomics. Food Technol. Biotechnol., 2008, 46, 1-10.

[58] López-Ferrer, D.; Hixson, K.K.; Smallwood, H.; Squier, T.C.; Petritis, K.; Smith, R.D. Evaluation of a high-intensity focused ultrasound-immobilized trypsin digestion and 180-labeling method for quantitative proteomics. Anal. Chem., 2009, 81, 6272-6277.

[59] Ortea, I.; Cañas, B.; Gallardo, J.M. Selected tandem mass spectrometry ion monitoring for the fast identification of seafood species. J. Chromatogr. A, 2011, 1218, 4445-4451.

[60] Pischetsrieder, M.; Baeuerlein, R. Proteome research in food science. Chem. Soc. Rev., 2009, 38, 2600-2608.

[61] Bauchart, C.; Chambon, C.; Mirand, P.P.; Savary-Auzeloux, I.; Rémond, D.; Morzel, M. Peptides in rainbow trout (Oncorhynchus mykiss) muscle subjected to ice storage and cooking. Food Chem., 2007, 100, 1566-1572.

[62] Ryan, J.T.; Ross, R.P.; Bolton, D.; Fitzgerald, G.F.; Stanton, C. Bioactive peptides from muscle sources: meat and fish. Nutrients, 2011, 3, 765-791.

[63] Suetsuna, K.; Osajima, K. The inhibitory activities against angiotensin I-converting enzyme of basic peptides originating from sardine and hair tail meat. Nippon Suisan Gakk., 1986, 52, 19811984.

[64] Carrera, M.; Cañas, B.; Gallardo, J.M. The sarcoplasmic fish proteome: Pathways, metabolic networks and potential bioactive peptides for nutritional inferences. J. Proteomics, 2013, 78, 211220.

[65] Panchaud, A.; Affolter, M.; Kussmann, M. Mass spectrometry for nutritional peptidomics: How to analyze food bioactives and their health effects. J. Proteomics, 2012, 75, 3546-3559.

[66] Schindler, A.; Dunkel, A.; Stähler, F.; Backes, M.; Ley, J.; Meyerhof, W.; Hofmann, T. Discovery of salt taste enhancing arginyl dipeptides in protein digests and fermented fish sauces by means of a sensomics approach. J. Agric. Food Chem., 2011, 59, $12578-12588$.

[67] Amagliani, G.; Brandi, G.; Schiavano, G.F. Incidence and role of Salmonella in seafood safety. Food Res. Int., 2012, 45, 780-788.

[68] Visciano, P.; Schirone, M.; Tofalo, R.; Suzzi, G. Biogenic amines in raw and processed seafood. Front. Microbiol., 2012, 3, 188.

[69] MacKenzie, L.; Beuzenberg, V.; Holland, P.; McNabb, P.; Selwood, A. Solid phase adsorption toxin tracking (SPATT): a new monitoring tool that simulates the biotoxin contamination of filter feeding bivalves. Toxicon, 2004, 44, 901-918.

[70] García-Altares, M.; Diogène, J.; de la Iglesia, P. The implementation of liquid chromatography tandem mass spectrometry for the official control of lipophilic toxins in seafood: Single-laboratory validation under four chromatographic conditions. J. Chromatogr. A, 2013, 1275, 48-60.

[71] Rehmann, N.; Hess, P.; Quilliam, M.A. Discovery of new analogs of the marine biotoxin azaspiracid in blue mussels (Mytilus edulis) by ultra-performance liquid chromatography/tandem mass spectrometry. Rapid Commun. Mass Spectrom., 2008, 22, 549-558.

[72] de la Iglesia, P.; McCarron, P.; Diogene, J.; Quilliam, M.A. Discovery of gymnodimine fatty acid ester metabolites in shellfish using liquid chromatography/mass spectrometry. Rapid Commun. Mass Spectrom., 2013, 27, 643-653.

[73] James, K.J.; Gillman, M.; Amandi, M.F.; López-Rivera, A. Puente, P.F.; Lehane, M.; Mitrovic, S.; Furey, A. Amnesic shellfish poisoning toxins in bivalve molluscs in Ireland. Toxicon, 2005, 46, 852-858

[74] Malécot, M.; Marie, A.; Puiseux-Dao, S.; Edery, M. iTRAQ-based proteomic study of the effects of microcystin-LR on medaka fish liver. Proteomics, 2011, 11, 2071-2078.

[75] Ferranti, P.; Nasi, A.; Bruno, M.; Basile, A.; Serpe, L.; Gallo, P. A peptidomic approach for monitoring and characterising peptide cyanotoxins produced in Italian lakes by matrix-assisted laser desorption/ionisation and quadrupole time-of-flight mass spectrometry. Rapid Commun. Mass Spectrom., 2011, 25, 11731183.

[76] Li, L.; Xie, P.; Guo, L.; Ke, Z.; Zhou, Q.; Liu, Y.; Qiu, T. Field and laboratory studies on pathological and biochemical characterization of microcystin-induced liver and kidney damage in the phytoplanktivorous bighead carp. ScientificWorldJournal, 2008, 8, 121-37.

[77] Falconer, I.R. Tumor promotion and liver-injury caused by oral consumption of cyanobacteria. Environ. Toxic. Water, 1991, 6, 177-184.

[78] Devesa, V.; Martinez, A.; Suner, M.A.; Velez, D.; Almela, C.; Montoro, R. Effect of cooking temperatures on chemical changes in species of organic arsenic in seafood. J. Agr. Food Chem., 2001, 49, 2272-2276.

[79] Falco, G.; Bocio, A.; Domingo, J.L. Exposure to polycyclic aromatic hydrocarbons through consumption of edible marine species in Catalonia, Spain. J. Food Prot., 2006, 69, 7p.

[80] Patandin, S.; Lanting, C.I.; Mulder, P.G.; Boersma, E.R.; Sauer, P.J.; Weisglas-Kuperus, N. Effects of environmental exposure to polychlorinated biphenyls and dioxins on cognitive abilities in Dutch children at 42 months of age. J. Pediatr., 1999, 134, 33-41.

[81] Heijne, W.H.M.; Kienhuis, A.S.; van Ommen, B.; Stierum, R.H.; Groten, J.P. Systems toxicology: applications of toxicogenomics, transcriptomics, proteomics and metabolomics in toxicology. Expert. Rev. Proteomics, 2005, 2, 767-780.

[82] Yadetie, F.; Karlsen, O.A.; Lanzen, A.; Berg, K.; Olsvik, P.; Hogstrand, C.; Goksoyr, A. Global transcriptome analysis of Atlantic cod (Gadus morhua) liver after in vivo methylmercury exposure suggests effects on energy metabolism pathways. Aquat. Toxicol., 2013, 126, 314-325.

[83] Bohne-Kjersem, A.; Skadsheim, A.; Goksoyr, A.; Grosvik, B.E. Candidate biomarker discovery in plasma of juvenile cod (Gadus morhua) exposed to crude North Sea oil, alkyl phenols and polycyclic aromatic hydrocarbons (PAHs). Mar. Environ. Res., 2009, 68, 268-277.

[84] Mi, J.; Apraiz, I.; Cristobal, S. Peroxisomal proteomic approach for protein profiling in blue mussels (Mytilus edulis) exposed to crude oil. Biomarkers, 2007, 12, 47-60.

[85] Olsson, B.; Bradley, B.P.; Gilek, M.; Reimer, O.; Shepard, J.L.; Tedengren, M. Physiological and proteomic responses in Mytilus 
edulis exposed to PCBs and PAHs extracted from Baltic Sea sediments. Hydrobiologia, 2004, 514, 15-27.

[86] Rodríguez-Ariza, A.; Rodríguez-Ortega, M.J.; Marenco, J.L.; Amezcua, O.; Alhama, J.; López-Barea, J. Uptake and clearance of PCB congeners in Chamaelea gallina: response of oxidative stress biomarkers. Comp. Biochem. Physiol. C Toxicol. Pharmacol., 2003, 134, 57-67.

[87] Rodriguez-Ortega, M.J.; Grosvik, B.E.; Rodriguez-Ariza, A.; Goksoyr, A.; Lopez-Barea, J. Changes in protein expression profiles in bivalve molluscs (Chamaelea gallina) exposed to four model environmental pollutants. Proteomics, 2003, 3, 1535-43.

[88] Chora, S.; Starita-Geribaldi, M.; Guigonis, J.-M.; Samson, M.; Roméo, M.; Bebianno, M.J. Effect of cadmium in the clam Ruditapes decussatus assessed by proteomic analysis. Aquat. Toxicol., 2009, 94, 300-308.

[89] Bjørnstad, A.; Larsen, B.K.; Skadsheim, A.; Jones, M.B.; Andersen, O.K. The potential of ecotoxicoproteomics in environmental monitoring: biomarker profiling in mussel plasma using proteinchip array technology. J. Toxicol. Environ. Health A, 2006, 69, 77-96.

[90] Zarei, M.; Maktabi, S.; Ghorbanpour, M. Prevalence of Listeria monocytogenes, Vibrio parahaemolyticus, Staphylococcus aureus, and Salmonella spp. in seafood products using multiplex polymerase chain reaction. Foodborne Pathog. Dis., 2012, 9, 108112.

[91] Hazen, T.H.; Martinez, R.J.; Chen, Y.F.; Lafon, P.C.; Garrett, N.M.; Parsons, M.B.; Bopp, C.A.; Sullards, M.C.; Sobecky, P.A. Rapid identification of Vibrio parahaemolyticus by whole-cell matrix-assisted laser desorption ionization-time of flight mass spectrometry. Appl. Environ. Microbiol., 2009, 75, 6745-6756.

[92] Wang, F.; Jiang, L.; Yang, Q.R.; Han, F.F.; Chen, S.Y.; Pu, S.H.; Vance, A.; Ge, B.L. Prevalence and antimicrobial susceptibility of major foodborne pathogens in imported seafood. J. Food Prot., 2011, 74, 1451-1461.

[93] Cordwell, S.J.; Len, A.C.L.; Touma, R.G.; Scott, N.E.; Falconer, L.; Jones, D.; Connolly, A.; Crossett, B.; Djordjevic, S.P. Identification of membrane-associated proteins from Campylobacter jejuni strains using complementary proteomics technologies. Proteomics, 2008, 8, 122-139.

[94] Fagerquist, C.K.; Garbus, B.R.; Williams, K.E.; Bates, A.H.; Boyle, S.; Harden, L.A. Web-based software for rapid top-down proteomic identification of protein biomarkers, with implications for bacterial identification. Appl. Environ. Microbiol., 2009, 75, 4341-4353.

[95] Martínez-Gomariz, M.; Hernáez, M.L.; Gutiérrez, D.; XiménezEmbún, P.; Préstamo, G. Proteomic analysis by two-dimensional differential gel electrophoresis (2D DIGE) of a high-pressure effect in Bacillus cereus. J. Agric. Food Chem., 2009, 57, 3543-3549.

[96] Fernández-No, I.C.; Böhme, K.; Calo-Mata, P.; Cañas, B.; Gallardo, J.M.; Barros-Velázquez, J. Isolation and characterization of Streptococcus parauberis from vacuum-packaging refrigerated seafood products. Food Microbiol., 2012, 30, 91-97.

[97] Böhme, K.; Fernández-No, I.C.; Barros-Velázquez, J.; Gallardo, J.M.; Calo-Mata, P.; Cañas, B. Species differentiation of seafood spoilage and pathogenic gram-negative bacteria by MALDI-TOF mass fingerprinting. J.Proteome Res., 2010, 9, 3169-3183.

[98] Böhme, K.; Fernández-No, I.C.; Barros-Velázquez, J.; Gallardo, J.M.; Cañas, B.; Calo-Mata, P. Rapid species identification of seafood spoilage and pathogenic Gram-positive bacteria by MALDI-TOF mass fingerprinting. Electrophoresis, 2011, 32, 2951-2965.

[99] Mazzeo, M.F.; Sorrentino, A.; Gaita, M.; Cacace, G.; Di Stasio, M.; Facchiano, A.; Comi, G.; Malorni, A.; Siciliano, R.A. Matrixassisted laser desorption ionization-time of flight mass spectrometry for the discrimination of food-borne microorganisms. Appl. Environ. Microbiol., 2006, 72, 1180-1189.

[100] Teshima, R. Hypersensitivity about environmental chemicals-mainly about food allergy. Kokuritsu Iyakuhin Shokuhin Eisei Kenkyujo hokoku, 2001, 119, 27-39.

[101] Poms, R.E.; Klein, C.L.; Anklam, E. Methods for allergen analysis in food: a review. Food Addit. Contam. 2004, 21, 1-31.

[102] Aiello, D.; De Luca, D.; Gionfriddo, E.; Naccarato, A.; Napoli, A.; Romano, E.; Russo, A.; Sindona, G.; Tagarelli, A. Review: multistage mass spectrometry in quality, safety and origin of foods. Eur. J. Mass Spectrom. (Chichester, Eng), 2011, 17, 1-31.
[103] Yagami, T.; Haishima, Y.; Tsuchiya, T.; Tomitaka-Yagami, A.; Kano, H.; Matsunaga, K. Proteomic analysis of putative latex allergens. Int. Arch. Allergy Immunol., 2004, 135, 3-11.

[104] Swoboda, I.; Bugajska-Schretter, A.; Verdino, P.; Keller, W.; Sperr, W. R.; Valent, P.; Valenta, R.; Spitzauer, S. Recombinant carp parvalbumin, the major cross-reactive fish allergen: A tool for diagnosis and therapy of fish allergy. J. Immunol., 2002, 168, 45764584.

[105] Griesmeier, U.; Vázquez-Cortés, S.; Bublin, M.; Radauer, C.; Ma, Y.; Briza, P.; Fernández-Rivas, M.; Breiteneder, H. Expression levels of parvalbumins determine allergenicity of fish species. Allergy, 2010, 65, 191-198.

[106] Ma, Y.; Griesmeier, U.; Susani, M.; Radauer, C.; Briza, P.; Erler, A.; Bublin, M.; Alessandri, S.; Himly, M.; Vàzquez-Cortés, S.; Rincon de Arellano, I.R.; Vassilopoulou, E.; Saxoni-Papageorgiou, P.; Knulst, A. C.; Fernández-Rivas, M.; Hoffmann-Sommergruber, K.; Breiteneder, H. Comparison of natural and recombinant forms of the major fish allergen parvalbumin from cod and carp. Mol. Nutr. Food Res., 2008, 52, S196-S207.

[107] Nakamura, R.; Satoh, R.; Nakajima, Y.; Kawasaki, N.; Yamaguchi, T.; Sawada, J.-i.; Nagoya, H.; Teshima, R. Comparative study of $\mathrm{GH}$-transgenic and non-transgenic amago salmon (Oncorhynchus masou ishikawae) allergenicity and proteomic analysis of amago salmon allergens. Regul. Toxicol. Pharmacol., 2009, 55, 300-308.

[108] Richardson, R.C.; King, N.M.; Sun, H.; Nelson, D.J.; Harrington, D.J.; Royer, W.E. X-ray crystal structure and molecular dynamics simulations of silver hake parvalbumin (Isoform B). Protein Sci., 2000, 9, 73-82.

[109] Leung, P.S.; Chen, Y.C.; Chu, K.H. Seafood allergy: tropomyosins and beyond. J. Microbiol. Immunol. Infect., 1999, 32, 143-54.

[110] Piñeiro, C.; Barros-Velázquez, J.; Vázquez; Figueras, A. Proteomics as a tool for the investigation of seafood and other marine products. J. Proteome Res., 2002, 2, 127-135.

[111] Perez-Gordo, M.; Cuesta-Herranz, J.; Maroto, A.S.; Cases, B.; Ibáñez, M.D.; Vivanco, F.; Pastor-Vargas, C. Identification of sole parvalbumin as a major allergen: study of cross-reactivity between parvalbumins in a Spanish fish-allergic population. Clin. Exp. Allergy, 2011, 41, 750-758.

[112] Van Do, T.; Elsayed, S.; Florvaag, E.; Hordvik, I.; Endresen, C., Allergy to fish parvalbumins: Studies on the cross-reactivity of allergens from 9 commonly consumed fish. J. Allergy Clin. Immunol., 2005, 116, 1314-1320.

[113] Carrera, M.; Cañas, B.; Piñeiro, C.; Vázquez, J.; Gallardo, J.M. Identification of commercial hake and grenadier species by proteomic analysis of the parvalbumin fraction. Proteomics, 2006, 6, 5278-5287.

[114] Carrera, M.n.; Cañas, B.; Vázquez, J.s.; Gallardo, J.M. Extensive de novo sequencing of new parvalbumin isoforms using a novel combination of bottom-up proteomics, accurate molecular mass measurement by FTICR-MS, and selected MS/MS Ion monitoring. J. Proteome Res., 2010, 9, 4393-4406.

[115] Taka, H.; Kaga, N.; Fujimura, T.; Mineki, R.; ImaiZumi, M.; Suzuki, Y.; Suzuki, R.; Tanokura, M.; Shindo, N.; Murayama, K. Rapid determination of parvalbumin amino acid sequence from Rana catesbeiana (pI 4.78) by combination of ESI mass spectrometry, protein sequencing, and amino acid analysis. $J$. Biochem., 2000, 127, 723-729.

[116] Leung, N.H.; Wai, C.Y.; Shu, S.; Wang, J.; Kenny, T.; Chu, K.; Leung, P.C. Current immunological and molecular biological perspectives on seafood allergy: a comprehensive review. Clinic. Rev. Allerg. Immunol., 2012, 1-18.

[117] Motoyama, K.; Ishizaki, S.; Nagashima, Y.; Shiomi, K. Cephalopod tropomyosins: Identification as major allergens and molecular cloning. Food Chem. Toxicol., 2006, 44, 1997-2002.

[118] Yu, C.-J.; Lin, Y.-F.; Chiang, B.-L.; Chow, L.-P. Proteomics and immunological analysis of a novel shrimp allergen, Pen m 2. J. Immunol., 2003, 170, 445-453.

[119] Yunginger, J.W.; Sweeney, . K.G.; Sturner, W.Q.; Giannandrea, L.A.; Teigland, J.D.; Bray, M., Benson, P.A.; York, J.A., Biedrzycki, L.; Squillace, D.L.; Helm, R.M. Fatal food-induced anaphylaxis. JAMA, 1988, 260, 1450-1452.

[120] Clark, S.; Bock, S.A.; Gaeta, T.J.; Brenner, B.E.; Cydulka, R.K.; Camargo, C.A. Multicenter study of emergency department visits for food allergies. J. Allergy Clin. Immunol., 2004, 113, 347-352.

[121] Ortea, I.; Cañas, B.; Gallardo, J.M. Mass spectrometry characterization of species-specific peptides from arginine kinase 
for the identification of commercially relevant shrimp species. $J$. Proteome Res., 2009, 8, 5356-5362.

[122] Rahman, A.M.A.; Kamath, S.; Lopata, A.L.; Helleur, R.J. Analysis of the allergenic proteins in black tiger prawn (Penaeus monodon) and characterization of the major allergen tropomyosin using mass spectrometry. Rapid Commun. Mass Spectrom., 2010, 24, 24622470 .

[123] Stevenson, S.E.; Chu, Y.; Ozias-Akins, P.; Thelen, J.J. Validation of gel-free, label-free quantitative proteomics approaches: Applications for seed allergen profiling. J. Proteomics, 2009, 72, 555-566.

Received: October 13, 2013 Revised: October 13, $2013 \quad$ Accepted: November 19, 2013 